\title{
Relationship between Epoxy Resin Properties and Weepage of Glass-Reinforced Filament-Wound Pipes
}

\author{
C. Barrère-Tricca', J.-L. Halary² and F. Dal Maso 3 \\ 1 Institut français du pétrole, division Chimie et Physico-Chimie appliquées, 1 et 4, avenue de Bois-Préau, 92852 Rueil-Malmaison Cedex - France \\ 2 ESPCI, Laboratoire de physico-chimie structurale et macromoléculaire, 10, rue Vauquelin, 75231 Paris Cedex 05 - France \\ 3 Axson France, Zl des Béthunes, Rue de l'Équerre, Saint-Ouen-l'Aumône, BP 444, 95005 Cergy Cedex - France \\ e-mail: cecile.barrere-tricca@ifp.fr - jean-louis.halary@espci.fr - f.dalmaso@axson.fr
}

Résumé - Relation entre les propriétés de la résine et le phénomène de perlage de tubes composites verre-époxy - Afin de mieux comprendre le rôle de la matrice sur le phénomène de perlage de tubes composites, une démarche complète a été suivie, allant de la chimie des résines époxy à la mécanique de tubes composites sous pression, en passant par une étape intermédiaire de caractérisation d'échantillons composites plans. Quatre formulations présentant des propriétés mécaniques en traction très différentes ont été sélectionnées. L'étude de composites unidirectionnels plans a montré que la rupture en traction transverse se produit essentiellement par décohésion fibre/matrice. L'allongement à rupture des composites unidirectionnels plans en traction transverse est d'autant plus élevé que l'allongement de la résine à la rupture de l'interface fibre/matrice est grand. Des essais en pression interne avec effet de fond sur tubes composites bobinés à $\pm 55^{\circ}$ ont montré que le perlage provient de la rupture des monocouches unidirectionnelles perpendiculairement aux fibres constituant la paroi du tube. Un critère simple de perlage a été proposé : le perlage apparaît pour une pression directement proportionnelle à l'allongement à rupture des composites unidirectionnels plans en traction transverse. La constante de proportionnalité dépend de la géométrie du tube.

\begin{abstract}
Relationship between Epoxy Resin Properties and Weepage of Glass-Reinforced Filament-Wound Pipes - This study aims to understand the relationship between mechanical properties of a resin and weepage (loss of water tightness) of glass-reinforced filament-wound pipes. A three-stage study has been carried out, from epoxy resin chemistry to mechanical behaviour of composite pipes under pressure. Four resin formulations were selected by accounting for their different mechanical characteristics in tension. The study of unidirectional composite plaques showed that fracture in tension transversally to the fibre direction essentially comes from the failure of the fibre/matrix interface. The failure strain of these plaques is higher when the strain of the resin at failure of the fibre/matrix interface is higher. Biaxial pressure tests on $\pm 55^{\circ}$-filament-wound pipes revealed that weepage is due to the transversal failure of unidirectional layers of the pipe wall. Moreover, a very simple weepage criterion was proposed: weepage appears for a pressure directly proportional to the failure strain of unidirectional composite plaques in tension transversally to the fibre direction. The proportionality constant depends on the pipe geometry.
\end{abstract}




\section{INTRODUCTION}

Weepage results in the loss of water tightness of a composite pipe, arising with the occurring, at its surface, of droplets or fine jets of the transported fluid. As this phenomenon is not well controlled, it ensues an important over-design and in fine a cost increase for this kind of pipes. To face up to this difficulty, studies have been undertaken for around thirty years to try to understand the weepage phenomenon (Barrère-Tricca, 1998). The parameters responsible for weepage are not yet understood, even if all agree that it can be mostly explained by a damage transversally to the fibre direction (failure of the fibre/matrix interface and/or failure of the matrix). While numerous criteria exist to calculate the failure of a unidirectional layer (Berthelot, 1992), there is still no criterion allowing to design a pipe at weepage; moreover no idea was proposed to increase significantly the weepage pressure of such pipes.

The most common loading mode in industrial applications is internal pressure with end-effect (free ends), for which hoop stress is twice the axial stress. It was shown in theory (Greenwood, 1977) and experimentally (Spencer and Hull, 1977/1978) that the optimal winding angle to withstand internal pressure with end-effect is $\pm 55^{\circ}$ with regard to the pipe axis: limit of linearity of the stress-strain curves, pipe whitening, weepage and burst are maximum for an angle of $\pm 55^{\circ}$.

Pabiot et al. (1994) studied the influence of the fibre/ matrix interface on the weepage of filament-wound composite pipes. Glass-epoxy composites differing only by the nature of sizing agents were studied. These authors tried to correlate the weepage tests results to the energies of crack initiation and propagation in mode I, obtained from unidirectional composite samples, subjected to uniaxial tensile loading. The sample which presents the highest energy of crack initiation also presents the weakest energy of crack propagation. The corresponding pipe is characterised, on one hand, by the highest pressure at first damage (end of linearity of the stress-strain curve), on the other hand, by the smallest difference between the end-of-linearity pressure and the weepage pressure. These correlations show that the mechanical damage of glass-epoxy composite pipes subjected to internal pressure with end-effect results from mechanisms very influenced by the interface: crack initiation and propagation through the wall thickness.

Some authors were interested in the influence of the mechanical properties of the resin on the weepage phenomenon. Tanigushi et al. (1991) observed that the weepage pressure of glass-epoxy composite pipes is proportional to the failure strain of the resin. Mieras (1973) showed that the pressure at the end of linearity and the weepage pressure are higher when the failure stress of the resin is higher, for resins having the same failure strains. Also, when the failure stresses are equal, a more brittle resin (lower failure strain) presents lower first damage and weepage pressures. Nevertheless, the weepage would depend more on the failure stress than on the failure strain of the resin. Ghorbel (1990) studied pipes made from two different resins. The " $\mathrm{A}$ " resin has a failure strength and an elongation at failure higher than the " $\mathrm{B}$ " resin. The best plasticity of the A matrix leads to a pipe with a better weepage resistance and a higher linearity threshold.

\section{STUDY OF THE RESINS}

\subsection{Materials}

Two epoxy resins based on DGEBA (diglycidyl ether of bisphenol A) were studied. One is cured by DDS (4,4'-diaminodiphenyl sulfone) hardener whereas the other is cured by NMA (nadic methyl anhydride) hardener catalysed by BDMA (benzyldimethylamine) with the following proportion by weight: 100 parts of DGEBA, 90 parts of NMA and 2 parts of BDMA.

A bibliographical study on epoxy resins allowed us to establish how to control the structure and/or the morphology of DGEBA/DDS and DGEBA/NMA systems. The aim was to obtain resins presenting very different mechanical properties.

In the case of DGEBA/DDS systems, two ways were chosen to control the crosslink density. On one hand, five different ratios $p$ (number of atoms of hydrogen resulting from the amine functions/number of epoxy functions) were used:

- $p=1$ : i.e. stoichiometric mixture;

- $p=1.15$ and $p=1.3$ : i.e. mixtures with excess of amine;

$-p=0.85$ and $p=0.7$ : mixtures with excess of epoxy.

On the other hand, a chain expander, DMDDS (2-(n-methyl 4 aminophenyl) sulfone), of the same chemical structure as DDS, was synthesised and incorporated into the network (60\% of the NH functions brought by DMDDS).

As regards the DGEBA/NMA system, a liquid elastomer of CTBN type (copolymer of butadiene and acrylonitrile with carboxyl endings) was added with the following ratios: $15 \%$ and $30 \%$ by weight with regard to the catalysed mixture DGEBA/NMA.

\subsection{Samples}

The curing cycles of resins were optimised to reach the highest glass-transition temperature without thermal degradation:

- $6 \mathrm{~h}$ at $150^{\circ} \mathrm{C}$ followed by $3 \mathrm{~h}$ at $200^{\circ} \mathrm{C}$ for DGEBA/ DDS-based formulations;

- $5 \mathrm{~h}$ at $90^{\circ} \mathrm{C}$ followed by $2 \mathrm{~h}$ at $140^{\circ} \mathrm{C}$ for DGEBA/NMAbased formulations.

The temperature rate between the different steps $\left(10^{\circ} \mathrm{C} / \mathrm{h}\right)$ was chosen in order to limit the residual thermal stresses. These curing cycles were also used for the composite products (plaques and pipes). 


\subsection{Results and Discussion}

\subsubsection{Molecular Mobility}

Loss modulus $E^{\prime \prime}$ and storage modulus $E^{\prime}$ were measured by mechanical spectrometry (PL-DMTA Mark III) from $-150^{\circ}$ to $+250^{\circ} \mathrm{C}$. This allowed to study the molecular transitions (glass and secondary transitions) and to analyse their influence on the mechanical properties at small strains, such as the modulus of elasticity at room temperature. The loading mode used is the single-cantilever bending mode, with a 14-mm free length of the sample. The loading frequency is $1 \mathrm{~Hz}$ and the displacement amplitude is $16 \mu \mathrm{m}$. The heating rate is $2^{\circ} \mathrm{C} / \mathrm{min}$. Samples have a thickness of $2 \mathrm{~mm}$ and a width of $5 \mathrm{~mm}$.

For DGEBA/DDS-based formulations (for example, Figures 1 and 2 in the case of an excess of epoxy), the glasstransition temperature, $T_{g}$, increases with the crosslink density because the creation of crosslinks reduces the molecular mobility. Furthermore, the area of the glass-transition peak decreases with the crosslink density, because chains motions are more limited. At very low temperature, the storage modulus $E^{\prime}$ is higher as the density of reticulation is higher. This is related to the higher bulk density of the most cured systems, which confers to the material a higher storage modulus. After the $\beta$ secondary transition, the order of storage modulus is reversed and the more a system is crosslinked, the more its storage modulus is low. The inversion can be related to the area of the $\beta$ transition peak. The decrease of storage modulus is all the more important as the area of the peak is large, meaning that the number of hydroxypropylether sequences formed during the curing is high (Cukierman et al., 1991). At equal number of hydroxypropylether sequences, the mechanical losses are all the more important as the curing density is high, because of synergies in motions of dense systems (Cukierman et al., 1991).
For DGEBA/NMA/CTBN formulations, two glass transitions are observed, proving that a phase separation took place. The storage modulus $E^{\prime}$ at room temperature decreases with the quantity of CTBN introduced. This evolution can be linked to the area of the $E^{\prime \prime}$ peak of the glass transition of the phase rich in elastomer towards $-45^{\circ} \mathrm{C}$, which increases with the quantity of elastomer added to the resin.

\subsubsection{Tension Tests at Room Temperature}

Uniaxial tension tests were performed on an Instron 1122 machine equipped with a load cell of maximal capacity 1000 N. Displacements were measured by means of an extensometer with a reference length of $25 \mathrm{~mm}$. H2-type samples, $2 \mathrm{~mm}$ in thickness, were tested.

Tension tests have been performed at different strain rates (Barrère-Tricca, 1998). This allowed us to check that the resins used in this study present a viscoelastic behaviour typical for epoxy resins.

The order of moduli of elasticity $E_{m}$ is identical to the order of storage moduli $E^{\prime}$ : they are all the lower as the transitions at low temperature are large.

DGEBA/DDS-based formulations present a viscoelastic behaviour with no yield (Fig. 3) meaning that the resins are brittle. An excess of epoxy functions led to an increase of the failure stress and of the failure strain, $\left(\sigma_{m}\right)^{r}$ and $\left(\varepsilon_{m}\right)^{r}$, corresponding to a decrease of the brittleness of the resin when the crosslink density decreases. On the other hand, the excess of amine functions or the use of DMDDS chain expander led to an embrittlement of the material.

For DGEBA/NMA-based formulations (Fig. 4), the addition of elastomer led to a strong decrease of $E_{m}$ and $\left(\sigma_{m}\right)^{r}$ as well as a strong increase of $\left(\varepsilon_{m}\right)^{r}$. A yield threshold also appears. Pure DGEBA/NMA resin presents a viscoelastic behaviour without yield while DGEBA/NMA/CTBN systems have an elastoviscoplastic behaviour.

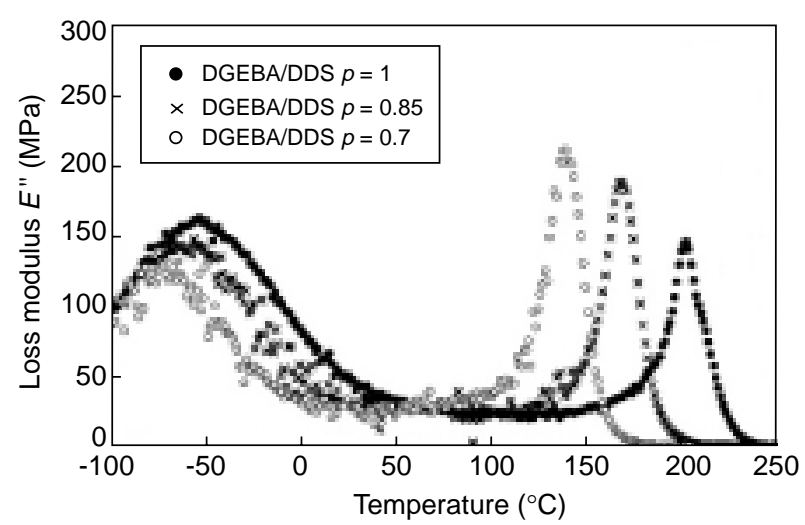

Figure 1

Loss modulus of resins $v s$. temperature.

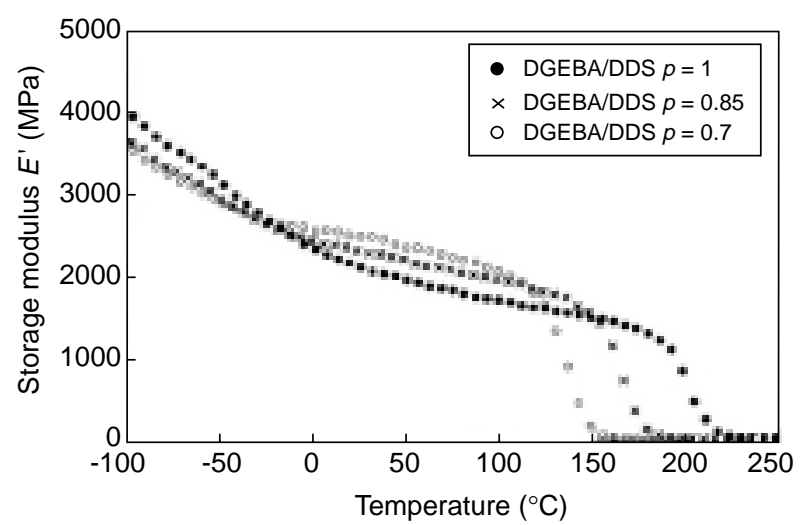

Figure 2

Storage modulus of resins vs. temperature. 


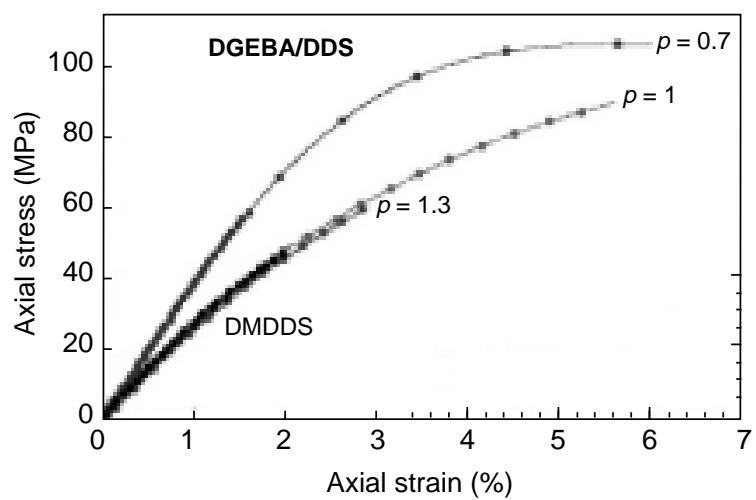

Figure 3

Uniaxial tensile stress-strain curves of resins for DGEBA/ DDS systems.

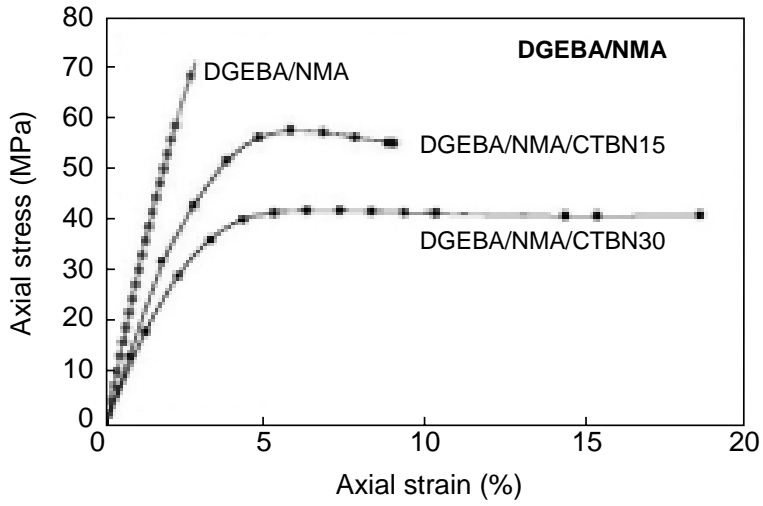

Figure 4

Uniaxial tensile stress-strain curves of resins for DGEBA/ NMA systems.
Four resin formulations presenting different mechanical properties in tension and viscosities adapted to the filamentwinding processing were chosen for the manufacture of composite products (DGEBA/DDS $p=1$ and $p=0.7$; DGEBA/ NMA and DGEBA/NMA/CTBN15). For these formulations, $E_{m}$ varies between $2200 \mathrm{MPa}$ and $3300 \mathrm{MPa},\left(\sigma_{m}\right)^{r}$ between $55 \mathrm{MPa}$ and $105 \mathrm{MPa}$ and $\left(\varepsilon_{m}\right)^{r}$ between $2.5 \%$ and $9 \%$.

\section{UNIDIRECTIONAL COMPOSITE PLAQUES}

\subsection{Materials}

Plaques of unidirectional composite of thickness $2 \mathrm{~mm}$ were prepared by compression moulding. They are made of six layers of unidirectional fabrics (mass: $420 \mathrm{~g} / \mathrm{m}^{2}$ ) manufactured by the Les fils d'Auguste Chomarat Company by using R25H 2400 tex threads from Owens-Corning Fibreglass. These are E-glass fibres modified to increase their resistance to ageing (ECRGLAS).

These plaques are of excellent quality and the volume fraction of fibres varies between $43 \%$ and $54 \%$.

\subsection{Tension Tests Transversally to the Fibre Direction at Room Temperature}

Samples are of dumb-bell type (type I, standard NF T 57-101). The tests are performed on an Instron 5568 machine equipped with a load cell of maximum capacity $50 \mathrm{kN}$, by following the standard NF T 57-101. The displacements are measured by means of an extensometer with a reference length of $25 \mathrm{~mm}$. The strain rate is $1.3 \cdot 10^{-3} \mathrm{~s}^{-1}$.

For composites with DGEBA/DDS matrices (Fig. 5), the decrease of the $p$ ratio (increase of the number of epoxy functions) leads to an increase of the modulus of elasticity, but no significant variation of the failure characteristics.
For composites with DGEBA/NMA matrices (Fig. 6), the addition of CTBN elastomer leads to a decrease of the modulus of elasticity as well as an important increase of the failure strain, from $0.5 \%$ to $1.1 \%$. One can also note a significant increase of non-linear behaviour for strains above $0.5 \%$, meaning an increase of the viscoelastic character of the composite.

For a given series (DGEBA/DDS or DGEBA/NMA), the order of the moduli of elasticity and of the failure characteristics remains unchanged between the pure resin and the composites. Whatever the system, the failure strain and the failure stress are lower for the unidirectional composites tested in transverse tension $\left(\left(\varepsilon_{2}\right)^{r}\right.$ and $\left.\left(\sigma_{2}\right)^{r}\right)$ than for the pure resin tested in tension $\left(\left(\varepsilon_{m}\right)^{r}\right.$ and $\left.\left(\sigma_{m}\right)^{r}\right)$. Several explanations have to be taken into account (Barrère-Tricca, 1998):

- the stress state of the resin is more severe in the composite than in the pure resin (triaxial stresses, thermal residual stresses);

- there is a phenomenon of strain amplification in the matrix. The fibre modulus being high by comparison with that of the pure resin, the deformation in the resin in the narrowest places between the nearby fibres is much more important than the global strain applied to the composite. Then, the failure of the composite appears for macroscopic deformations weaker than those expected;

- the failure of a unidirectional composite tested in transverse tension corresponds to the failure of the weakest link: the matrix (cohesive failure of the matrix) or the fibre/matrix interface (adhesive failure of the interface). The failure facies observed by using scanning electron microscopy (SEM) show two different behaviours according to the resin used: adhesive failure for DGEBA/DDS ( $p=1$ and $p=0.7$ ) and DGEBA/NMA/CTBN15 and mixed adhesive-cohesive failure for DGEBA/NMA;

- there are defects in the composite (non-uniform distribution of fibres, contiguous fibres, etc.); 


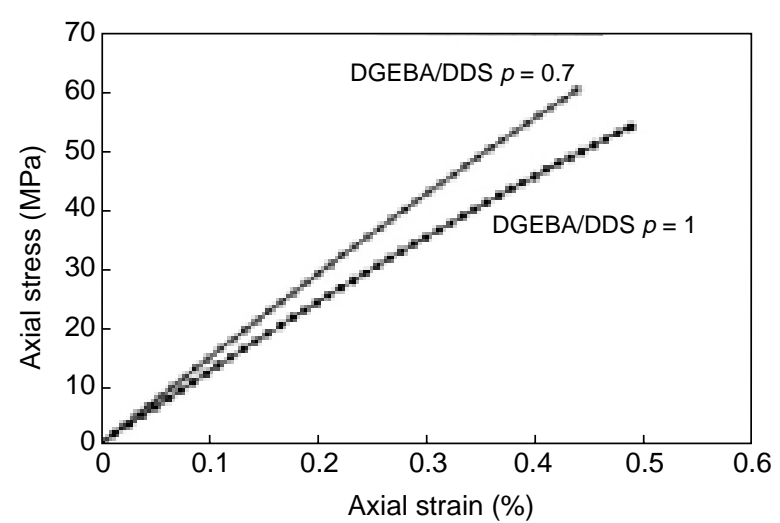

Figure 5

Transverse tensile curves of plane unidirectional composites for DGEBA/DDS systems.

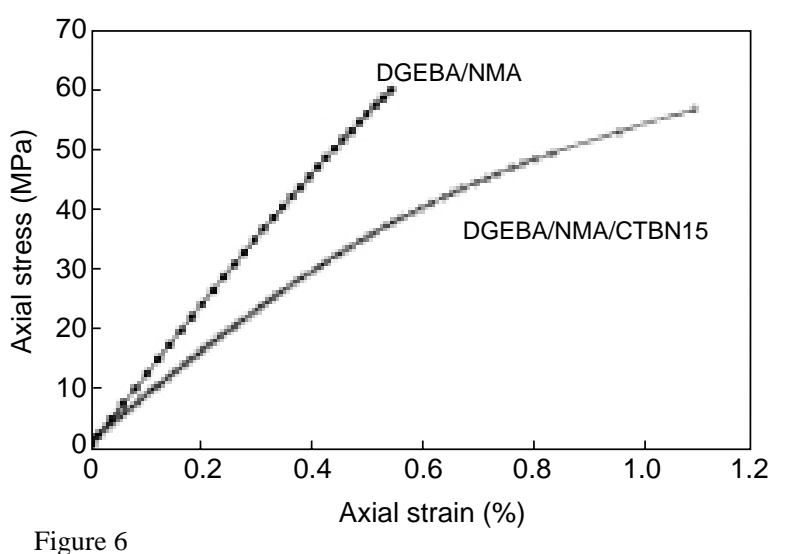

Transverse tensile curves of plane unidirectional composites for DGEBA/NMA systems.
- the mechanical properties of the pure resin and of the matrix are different because of structural and/or morphological modifications inferred by the incorporation of fibres.

\subsection{Discussion}

The failure stress is about $55 \mathrm{MPa}$ for all the unidirectional composites tested in transverse tension (Figs. 5 and 6), but a difference of behaviour is clearly observed between the DGEBA/NMA-based composites and the DGEBA/DDSbased composites. Indeed, the variation of the failure stress between the pure resin and the composite is very small for DGEBA/NMA and DGEBA/NMA/CTBN15 while it is much higher for DGEBA/DDS ( $p=1$ and $p=0.7$ ). This remark, combined with the SEM fracture facies observation, leads to the following proposition: the failure stress of the fibre/matrix interface is about $55 \mathrm{MPa}$ for composites made of DGEBA epoxy and glass fibres with universal sizing. Figure 7 presents a summary of this analysis. The tensile behaviour of DGEBA/DDS ( $p=1$ and $p=0.7$ ) resins is represented by the curve $r_{1}$. These resins present a high failure strain (about 6\%), but as their failure stress is much greater than the interface failure stress, the transverse failure of the composite is due to interfacial debonding and the resin is not used at its best capacities. The tension behaviour of the resin DGEBA/NMA is represented by the curve $r_{2}$. This resin presents a relatively small failure strain (about 2.3\%). In that case, the failure stress of the resin is slightly superior to that of the interface. The transverse failure of the composite is essentially due to interfacial debonding, but also to matrix failure because the failure stress of the resin and that of the interface are close. In this case, the resin is almost used at its highest capacities. Finally, the behaviour in tension of the resin DGEBA/NMA/CTBN15 is represented by the curve $r_{3}$. This resin presents a failure strain particularly high (8.4\%), but as its yield stress is slightly

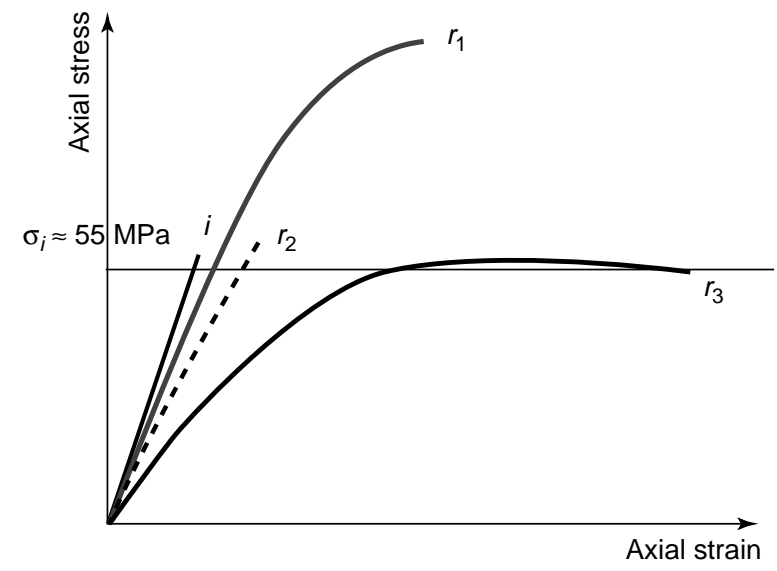

Figure 7

Tensile stress-strain curves for one interface $(i)$ and three resins $\left(r_{1}, r_{2}, r_{3}\right)$.

superior to the interface failure stress, the transverse failure of the composite is due to interfacial debonding and the resin is not used at its highest capacities. With the DGEBA/NMA/ CTBN15 matrix, the failure strain of the unidirectional composite tested in transverse tension $\left(\left(\varepsilon_{2}\right)^{r}=1.1 \%\right)$ is about twice as high as the three other matrices because the resin strain is high when the interface breaks. This results from the low modulus of the resin DGEBA/NMA/CTBN15 but also from its more marked non-elastic behaviour.

\section{WEEPAGE}

\subsection{Materials and Manufacturing of Pipes}

The glass-epoxy composite pipes were made at IFP by helicoidal filament winding, from stratifil 30 R25H 2400 tex from Owens-Corning Fibreglass. Pipes are made of two 
layers wound with the optimal angle of $\pm 55^{\circ}$. Their length is $600 \mathrm{~mm}$, their internal diameter $50 \mathrm{~mm}$ and their thickness $2 \mathrm{~mm}$. These pipes do not have any coating, either internal (liner) or external (top coat). Pipes are of good quality and their volume fraction of fibres varies between $55 \%$ and $59 \%$.

\subsection{Short-Term Tests under Increasing Internal Pressure}

Tests of static resistance under increasing internal pressure with free ends were made according to the standard ASTM D 1599-88. The test is stopped at weepage, which is detected visually on the pipe. The weepage pressures given in Table 1 are averages on three tests. The liquid used is water at $23^{\circ} \mathrm{C}$. The loading rate is $1 \mathrm{MPa} / \mathrm{min}$. The length of the tested pipes is $500 \mathrm{~mm}$. The global deformations of pipes (axial and hoop) are measured by means of gauges. The tests are stopped at weepage so that an expertise by SEM can be done.

\section{TABLE 1}

Weepage pressure for composite pipes

\begin{tabular}{l|c}
\hline & $P_{\text {weepage }}( \pm 0.3 \mathrm{MPa})$ \\
\hline DGEBA/DDS $p=1$ & 13.8 \\
DGEBA/DDS $p=0.7$ & 14.2 \\
DGEBA/NMA & 15.0 \\
DGEBA/NMA/CTBN15 & 32.2 \\
\hline
\end{tabular}

Pressure against strain curves is almost linear up to the weepage, either in axial direction or in hoop direction for pipes with DGEBA/DDS matrices ( $p=1$ and $p=0.7$ ) and DGEBA/NMA matrices. This seems to indicate that there is no considerable damage before weepage. Axial deformation deviates from linearity from $16 \mathrm{MPa}$ for pipes with DGEBA/NMA/CTBN15 matrices. The non-linearity of axial deformations also observed on the transverse tension curve of plane unidirectional composites results from the elastoviscoplasticity of the resin. The almost linearity of the curves in hoop direction for the formulation DGEBA/NMA/ CTBN15 can be explained by the fact that the behaviour of pipes in this direction is close to that of fibres. SEM photos (Fig. 8) show fibre/matrix debonding, cracks in the matrix, but no fracture of fibres nor delamination between the layers. The weepage results from the failure of layers in the direction perpendicular to the fibres (transverse failure). So, although the state of stress in pipes under pressure is more complex than that in unidirectional composite under transversal stress, the mechanisms of damage are similar. The comparison between the weepage pressure $P_{\text {weepage }}$ and the failure strain $\left(\varepsilon_{2}\right)^{r}$ measured in transverse tension on plane unidirectional composites was done. $P_{\text {weepage }}$ increases with $\left(\varepsilon_{2}\right)^{r}$ and the ratio $P_{\text {weepage }} /\left(\varepsilon_{2}\right)^{r}$ is equal to $3.0 \cdot 10^{3} \mathrm{MPa}$ (with a $10 \%$ error) for all the matrices used. We therefore proposed a simple weepage criterion for pipes with a winding angle of $55^{\circ}$ (optimal angle), tested in internal pressure with end-effect:

$$
P_{\text {weepage }}=A(e, D) *\left(\varepsilon_{2}\right)^{r}
$$

$A$ is a constant, which depends on the geometry of the pipe. Through $\left(\varepsilon_{2}\right)^{r}$, the weepage pressure is linked to the mechanical properties of the matrix and the fibre/matrix interface. To reach high weepage pressures and get closer to the burst pressure, it is necessary to use matrices presenting a high strain when the fibre/matrix interface breaks. Tables giving the value of $A$ according to the geometry of the pipe (thickness of the wall $e$ and internal diameter $D$ ) would therefore allow to evaluate the weepage pressure of a composite pipe, by a simple tensile test on a unidirectional composite plaque.
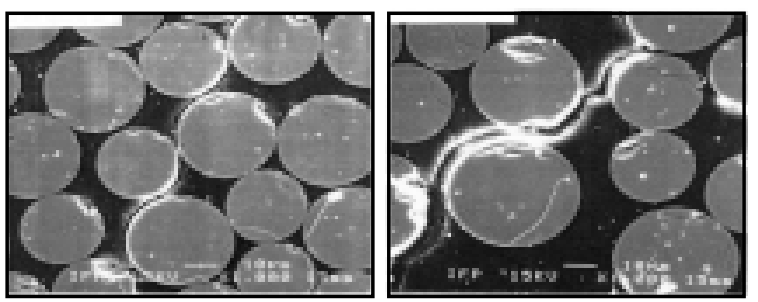

Figure 8

Composite pipe after weepage test (SEM, * 1000).

\section{CONCLUSION}

The aim of this study was to understand the relationship between mechanical properties of the resin and weepage (loss of water tightness) of glass-reinforced filament-wound pipes, in order to be able to propose methods to increase weepage pressure. A three-stage study has been undertaken, from epoxy resin chemistry to mechanical behaviour of composite pipes under pressure, by way of an intermediate stage of characterisation of plane unidirectional composites. It is this intermediate stage, not present in the other studies reported in literature, that allowed us to understand the influence of the matrix on pipe weepage.

For each resin studied, the modulus of elasticity at room temperature decreases with the quantity of molecular motions at low temperatures. For DGEBA/DDS resins, the stress and strain at failure increase with the excess of epoxy functions and decrease with the excess of amine functions or the use of the chain expander DMDDS. This leads to particularly interesting properties for the resin DGEBA/DDS ( $p=0.7$ ), containing a wide excess of epoxy functions, which presents stress and strain at failure relatively high for an epoxy resin. The DGEBA/NMA resins behave as brittle viscoelastic 
materials. The addition of a liquid elastomer in these resins results in an elastoviscoplastic behaviour typical of tough resins. Four resin formulations presenting very different mechanical properties were selected among those tested as matrices for composite products. These are DGEBA/DDS ( $p=1$ and $p=0.7$ ), DGEBA/NMA and DGEBA/NMA/ CTBN15.

To explain the failure stress and failure strain values for plane unidirectional composites tested in tension transversally to the fibre direction, we proposed that the failure stress of the fibre/matrix interface is around $55 \mathrm{MPa}$ for composites based on DGEBA and of fibreglasses ECR with universal sizing. Thanks to its high strain when the interface breaks, a plane unidirectional composite made with DGEBA/NMA/ CTBN15 resin exhibits a failure strain in transverse tension twice as high as the three other composites tested.

Biaxial pressure tests on $55^{\circ}$-filament-wound pipes have revealed that weepage is due to transverse failure of unidirectional layers of the pipe. Moreover, these tests have allowed to establish a very simple weepage criterion: weepage appears for a pressure directly proportional to the failure strain of the plane unidirectional composite in transverse tension. The proportionality constant depends on the pipe geometry. Therefore, the weepage pressure increases with the resin strain when the interface breaks.

All our results allow to choose the different ways to follow in order to increase the weepage pressure of composite pipes:

- to modify the resin formulation in order to increase its strain when the interface breaks; or

- to modify the sizing formulation in order to increase the failure stress of the interface.

\section{REFERENCES}

Barrère-Tricca, C. (1998) Relation entre les propriétés de la résine et le phénomène de weepage de pipes composites verreépoxy. $P h D$ Thesis, université Paris VI.

Berthelot, J.M. (1992) Matériaux composites : comportement mécanique et analyse des structures, Masson, Paris.

Cukierman, S., Halary, J.L. and Monnerie, L. (1991) Dynamic Mechanical Response of Model Epoxy Networks in the Glassy State. Polymer Engineering and Science, 31, 20, 1476-1482.

Ghorbel, I. (1990) Mécanismes d'endommagement des pipes verre-résine pour le transport d'eau chaude : influence de la ductilité de la matrice. $P h D$ Thesis, École nationale supérieure des mines de Paris.

Greenwood, J.H. (1977) German Work on GRP Design. Composites, 175-184.

Mieras, H.J.M.A. (1973) Irreversible Creep of Filament-Wound Glass-Reinforced Resin Pipes. Plastics \& Polymers, 41, 84-88.

Pabiot, J., Krawczak, P. and Monnier, C. (1994) Behaviour of Glass-Fibre Composite Pipes under Internal Pressure as a Function of Composite Cohesion Parameters. 49th Annual Conf. Composite Institute, The Society of the Plastic Industry, Inc., February 7-9.

Spencer, B. and Hull, D. (1978) Effect of Winding Angle on the Failure of Filament Wound Pipe. Composites, 9, 1, 263-271.

Tanigushi, K., Ohira, M. and Ishii, M. (1991) The Effect of Matrix Resins on the Mechanical Properties of Fibreglass Reinforced Pipes for Oil and Gas Production. 46th Annual Conf. Composite Institute, The Society of the Plastics Industry, Inc., February 18-21.

Final manuscript received in December 2001 